\title{
APPLICATION OF AHP TECHNIQUE
}

\author{
Valentinas Podvezko \\ Vilnius Gediminas Technical University, Saulètekio al. 11, LT-10223 Vilnius, Lithuania \\ E-mail: valentinas.podvezko@fm.vgtu.lt.
}

Received 20 October 2008; accepted 12 March 2009

\begin{abstract}
Recently, the use of multicriteria quantitative evaluation methods for solving social and economic problems has grown considerably. One of two major components of quantitative multicriteria evaluation methods strongly influencing the evaluation results is associated with the criteria weights. In practice, the criteria weights are determined in assessing the economic development of the state and its regions, the commercial activity and strategic potential of enterprises, the effectiveness of particular investment projects, etc. Several theoretical and practical methods of determining the significance (weight) of criteria by experts are known. Pairwise comparison of criteria is widely applied, and the most well-known, widely applied and mathematically grounded technique is the so-called Analytic Hierarchy Process (AHP). However, the application of this method is limited because of a great number of evaluation criteria, contradicting expert estimates and incompatible matrices obtained. In the present paper, the application of AHP technique to more complicated cases is considered and some algorithms are offered.
\end{abstract}

Keywords: criterion weight, AHP technique, multicriteria evaluation methods, the agreement between expert estimates.

\section{Introduction}

Social and economic problems associated with evaluation of social and economic development of states and regions, commercial activities and strategic potential of enterprises, as well as the comparison of investment projects based on their effectiveness, etc. are very complicated because of the specific nature of the considered phenomena. They cannot be measured or evaluated by a single quantity or criterion since there can hardly be found a feature integrating all essential properties of these phenomena. In recent years, the application of multicriteria quantitative evaluation methods to solving these problems has grown considerably (Figueira et al. 2005; Ginevičius 2008; Ginevičius et al. 2008b; Ginevičius, Podvezko 2007a, 2008a, 2008b; Kaklauskas et al. 2006, 2007a; Podvezko 2006, 2008; Ustinovichius et al. 2007; Zavadskas, Vilutiene 2006; Zavadskas et al. 2008a,b; Turskis et al. 2009).

Various methods of integrating the particular criteria describing the considered object into a single generalizing criterion have been offered and quite a few different multicriteria evaluation methods have been developed.
These methods are based on the statistical data on the criteria describing the compared objects (alternatives) $A_{j}(j=1,2, \ldots, n)$, or expert estimates and the criteria weights (significances) $\omega_{i}(i=1,2, \ldots, m)$, where $m$ is the number of criteria, $n$ is the number of the objects (alternatives) compared. The evaluation is aimed at ranking the alternatives $A_{j}$ by using quantitative multicriteria methods for the particular purpose of the research.

The criterion weights $\omega_{i}$ as one of two major components of quantitative multicriteria methods strongly influence the evaluation results. In practice, these weights are determined for assessing the economic development of various states and their regions (Ginevičius, Podvezko 2008c; Ginevičius et al. 2006), the effectiveness of commercial activities of enterprises and their strategic potential (Ginevičius, Podvezko 2006) as well as for comparing various investment projects and technologies (Ginevičius et al. 2007), etc.

The influence of the criteria describing a particular object with the aim of investigation differs considerably, therefore, the weights of the criteria used should be determined. Usually, the so-called subjective evalua- 
tion technique is applied, when the criteria weights are determined by experts, though objective and generalized evaluation methods are also used (Hwang, Yoon 1981; Ma et al. 1999).

The values of the criteria weights and the accuracy of evaluation results largely depend on the way of determining the criteria weights and the number of criteria because it is difficult for an expert to determine accurately the interrelationships between the criteria weights, when the number of criteria is continually growing.

There are several theoretical and practical approaches to determining the criteria weights by experts. These are ranking, direct weight determination and pairwise comparison (Zavadskas, Kaklauskas 2007; Ginevičius, Podvezko 2004, 2006; Kaklauskas et al. 2007b; Banaitiene et al. 2008; Viteikiene, Zavadskas 2007).

Pairwise comparison of criteria is a specific approach to determining the criteria weights. It is based on pairwise comparison of all evaluation criteria $R_{i}$ and $R_{j}(i$, $j=1,2, \ldots, m)$ by experts. The main advantage of this approach is a possibility to compare the criteria in pairs rather than all at a time. This method also allows the conversion of qualitative estimates elicited from experts to quantitative estimates, implying that the values of the criteria weights can be calculated.

The simplest methods use a two-point $0-1$ scale (when one criterion is more significant than another, or vice versa) (Beshelev, Gurvish 1974), while the most sophisticated and mathematically grounded AHP method developed by T. Saaty employs the scale of $1-3-5-7-9$ (Saaty 1980, 2005).

Methods of pairwise comparison have a good mathematical basis, however, they have not been widely used in Lithuania because they are too sophisticated. In recent years, researchers have shown more interest in this approach (Dikmen, Birgonul 2006; Cheng, Li 2004; Hsueh et al. 2007; Ginevičius, Podvezko 2007b; Mansouri et al. 2000; Vamvakeridou et al. 2006; Ginevičius et al. 2008a; Podvezko 2007; Su et al. 2006; Morkvenas et al. 2008). However, difficulties in filling in the questionnaires for comparing the criteria, the lack of agreement in the criterion evaluation matrices, etc. limited the application of the method. In fact, experts could properly fill in only a small percentage of questionnaires from the first time. Another problem is associated with a large number of evaluation criteria: determining the significance of a particular pair of criteria for the investigated object, an expert should mentally 'weigh' the importance of other pairs of criteria, which is a complicated problem when the number of criteria is more than ten.

The present paper aims to help the users of AHP method to fill in questionnaires of pairwise comparison of criteria properly, to identify logical inconsistencies in the filled in forms (if any) and to eliminate them. A method of determining the criteria weights in AHP approach, when the number of evaluation criteria is large, is also offered. For this purpose, the appropriate algorithms are presented. The main objective is to extend the range of AHP application by increasing the number of users.

\section{A description of analytical hierarchy process (AHP)}

Let us briefly describe the AHP approach.

It was suggested by Saaty (1980) and called Analytic Hierarchy Process (AHP). This method allows us to determine the weights (significances) of hierarchically non-structured or particular hierarchical level criteria in respect of those belonging to a higher level.

The method is based on the pairwise comparison matrix $\mathrm{P}=\left\|p_{i j}\right\|(i, j=1,2, \ldots, m)$. Experts compare all the evaluation criteria $R_{i}$ and $R_{j}(i, j=1,2, \ldots, m)$, where $m$ is the number of the criteria compared. In an ideal case, the elements of the matrix present the relationships between the unknown criteria weights:

$$
\mathbf{P}=\left(\begin{array}{ccc}
p_{11} & p_{12} \cdots & p_{1 m} \\
p_{21} & p_{22} \cdots & p_{2 m} \\
\vdots & & \vdots \\
p_{m 1} & p_{m 2} \cdots & p_{m m}
\end{array}\right)=\left(\begin{array}{ccc}
\frac{\omega_{1}}{\omega_{1}} & \frac{\omega_{1}}{\omega_{2}} \cdots & \frac{\omega_{1}}{\omega_{m}} \\
\frac{\omega_{2}}{\omega_{1}} & \frac{\omega_{2}}{\omega_{2}} \cdots & \frac{\omega_{2}}{\omega_{m}} \\
\vdots & & \vdots \\
\frac{\omega_{m}}{\omega_{1}} & \frac{\omega_{m}}{\omega_{2}} \cdots & \frac{\omega_{m}}{\omega_{m}}
\end{array}\right) .
$$

The comparison is qualitative and easy to perform. It indicates if one criterion is more significant than the other and to what level the priority belongs. The technique used allows the qualitative estimates elicited from experts to be converted to quantitative ones.

The technique is not complicated because it is easier to compare the criteria in pairs than all at a time. It is also well mathematically grounded.

The matrix $\mathrm{P}$ is an inverse symmetrical matrix, i.e. $p_{i j}=1 / p_{j i}$. It follows that the part of the matrix which is above the main diagonal or below it may be filled in. The number of non-recurrent elements of the $m$-order matrix $\mathbf{P}$, i.e. the number of elements com- 
pared is $m(m-1) / 2$ (the total number of the comparison matrix elements is equal to $m^{2}$ ).

The main principle of filling in the matrix is simple because an expert should indicate how much more important is a particular criterion than another. Saaty suggested a widely known 5-point scale (1-3-5-7-9) to be used for evaluation. The evaluation of the criteria ranges from $p_{i j}=1$, when $R_{i}$ and $R_{j}$ are equally significant, to $p_{i j}=9$, when the criterion $R_{i}$ is much more significant than the criterion $R_{j}$ with respect to the research aim (Saaty 1980, 2005).

In an ideal case, inverse symmetry of matrix $\mathbf{P}$ is evident: for example, if one object is five times as heavy as another, then, the latter is $1 / 5$ as heavy as the first object. In this case, the elements of any two matrix columns or rows will be proportional. This means that the relationships between the elements of the respective columns will be the same. For example, the relationships between the elements of the first and second columns are as follows:

$$
\frac{p_{i 1}}{p_{i 2}}=\frac{\frac{\omega_{i}}{\omega_{1}}}{\frac{\omega_{i}}{\omega_{2}}}=\frac{\omega_{2}}{\omega_{1}} \quad(i=1, \ldots, m) .
$$

A significant problem is to ensure the consistency of the matrix. The matrix $\mathbf{P}$ is consistent if from the minimal amount of its elements all other elements can be obtained. The elements of the columns (and rows) of a consistent matrix will be proportional.

The necessary condition of the comparison matrix consistency is transitivity of matrix elements' significance: if the element $\mathrm{A}$ is more significant than the element $\mathrm{B}$, while the element $\mathrm{B}$ is more significant than the element $\mathrm{C}$, then, the element $\mathrm{A}$ is more significant than the element $\mathrm{C}$. Under real conditions, it is not difficult, based on the condition of transitivity, to identify improperly filled in questionnaires because this condition is not fulfilled in them.

The condition required for a matrix to be in agreement may also be expressed in mathematical terms. In an ideal case, by using the equality (1), matrix $\mathbf{P}$ is multiplied by the column of weights, i.e. by the transposed row $\boldsymbol{\omega}=\left(\omega_{1}, \omega_{2}, \ldots, \omega_{m}\right)^{T}$ :

$$
\mathbf{P} \boldsymbol{\omega}=\left(\begin{array}{ccc}
p_{11} & p_{12} \cdots & p_{1 m} \\
p_{21} & p_{22} \cdots & p_{2 m} \\
\vdots & \ddots & \vdots \\
p_{m 1} & p_{m 2} \cdots & p_{m m}
\end{array}\right)\left(\begin{array}{l}
\omega_{1} \\
\omega_{2} \\
\cdots \\
\omega_{m}
\end{array}\right)=
$$

$$
=\left(\begin{array}{ccc}
\frac{\omega_{1}}{\omega_{1}} & \frac{\omega_{1}}{\omega_{2}} \ldots & \frac{\omega_{1}}{\omega_{m}} \\
\frac{\omega_{2}}{\omega_{1}} & \frac{\omega_{2}}{\omega_{2}} \ldots & \frac{\omega_{2}}{\omega_{m}} \\
\vdots & \ddots & \vdots \\
\frac{\omega_{m}}{\omega_{1}} & \frac{\omega_{m}}{\omega_{2}} \ldots & \frac{\omega_{m}}{\omega_{m}}
\end{array}\right)\left(\begin{array}{l}
\omega_{1} \\
\omega_{2} \\
\ldots \\
\omega_{m}
\end{array}\right)=\left(\begin{array}{l}
m \omega_{1} \\
m \omega_{2} \\
\ldots \\
m \omega_{m}
\end{array}\right)=m\left(\begin{array}{l}
\omega_{1} \\
\omega_{2} \\
\ldots \\
\omega_{m}
\end{array}\right)=m \boldsymbol{\omega},
$$

i.e. the well-known mathematical problem of matrix $\mathbf{P}$ eigenvalues with eigenvector $\boldsymbol{\omega}$ :

$$
\mathbf{P} \omega=\lambda \omega,
$$

where $\lambda=m$ is an eigenvalue, $m$ is the order of matrix $\mathbf{P}$, i.e. the number of the criteria compared.

The weights in Saaty's approach - the vector $\boldsymbol{\omega}$ are normalized components of eigenvector corresponding to the largest eigenvalue $\lambda_{\max }$ :

$$
\mathbf{P} \boldsymbol{\omega}=\lambda_{\max } \boldsymbol{\omega} .
$$

It is known (Saaty 1980) that the largest eigenvalue of the inverse symmetrical $m$-order matrix is $\lambda_{\max } \geq m$. In an ideal case, when the matrix is absolutely consistent and the elements of the columns are proportional, $\lambda_{\max }=m$. In this case, matrix consistency is characterized by the difference $\lambda_{\max }-m$ and the order $m$ of the matrix P. The AHP method assesses the consistency of each expert's estimates. Consistency index is defined (Saaty 1980, 2005; Ginevičius et al. 2004) as a relationship:

$$
S_{I}=\frac{\lambda_{\max }-m}{m-1}
$$

The smaller the consistency index, the higher the consistency of the matrix. In the ideal case, $S_{I}=0$. In fact, the ideally consistent matrix is a rare case, even if transitivity of its elements has been checked. The consistency degree of matrix $\mathbf{P}$ may be determined quantitatively by comparing the calculated consistency index of the matrix with a randomly generated consistency index (based on the scale 1-3-5-7-9) of the inverse symmetrical matrix of the same order. The values of the random consistency index $S_{A}$ are given in Table 1. In the first row of the table, the order of the comparison matrix is indicated, while, in the second row of the table, the average consistency index values are presented (Saaty 1980).

Inverse second-order symmetrical matrices are always consistent. The relationship between the calculated consistency index $S_{I}$ of a particular matrix and the 
Table 1. The values of a random consistency index

\begin{tabular}{cccccccccccccc}
\hline Matrix order & 3 & 4 & 5 & 6 & 7 & 8 & 9 & 10 & 11 & 12 & 13 & 14 & 15 \\
\hline$S_{A}$ & 0.58 & 0.90 & 1.12 & 1.24 & 1.32 & 1.41 & 1.45 & 1.49 & 1.51 & 1.48 & 1.56 & 1.57 & 1.59 \\
\hline
\end{tabular}

average random index value $S_{A}$ is referred to as consistency relationship. It determines the degree of matrix consistency:

$$
S=\frac{S_{I}}{S_{A}}
$$

The value of consistency index $S$ which is smaller than or equal to 0.1 is acceptable, implying that the matrix is consistent.

When the order of a comparison matrix is $m>15$, the average values of the random index $S_{A}$ may be roughly calculated by the formula (Taha 1997):

$$
S_{A}=\frac{1.98(m-2)}{m} .
$$

The estimates calculated by formula (7) are slightly larger than $S_{A}$ values given in Table 1. For example, when the matrix order is $m=15$, the average value of the random index calculated by formula (7) is $S_{A}=$ 1.72 (while, in the table, $S_{A}=1.59$ ).

\section{Calculation of the approximate weights by using AHP technique}

The AHP method is aimed at determining the significances (weights $\omega_{i}$ ) of the evaluation criteria and assessing the consistency of questionnaires elicited from experts, i.e. calculating consistency index $S_{I}$ and consistency relationship $S$ by formulas (5) and (6). For this purpose, a complicated practical eigenvalue problem should be solved as follows:

1) The characteristic equation of matrix $\mathbf{P}$ is formulated;

2) Eigenvalues of the matrix are calculated;

3) The largest eigenvalue $\lambda_{\max }$ is determined;

4) The eigenvector corresponding to the largest value is calculated;

5) The coordinates of the calculated vector are normalized (divided by their sum), thus yielding the weight $\omega_{i}$ of the criteria compared.

The eigenvalue problem is difficult to solve manually even for the third-order matrix, when only three criteria are compared. Therefore, special computer programs are used for this purpose. For example, when Visual Fortran and Microsoft Windows operating systems are employed, the program EVCGR is used.
However, even in the absence of computer programs, there is a possibility to calculate the approximate values of vector $\omega$ of the criteria weights and the respective largest eigenvalue $\lambda_{\text {max }}$. Saaty (1980), Shikin and Chartishvili (2000) offered a number of algorithms for calculating the criteria weights and the largest eigenvalue. The most accurate approach is associated with geometrical means of the products of the row elements of matrix $\mathbf{P}$. The following scheme of calculation is suggested:

1) Matrix $\mathbf{P}$ for comparing criteria by experts is constructed;

2) The products of the elements $\Pi_{i}=\prod_{j=1}^{m} p_{i j}(i=1$, $2, \ldots, m)$ of each $i$-th row of matrix $\mathbf{P}$ are found;

3) The $m$-th degree root $\sqrt[m]{\Pi_{i}}$ is extracted from the obtained products $\Pi_{i}$;

4) The values obtained are normalized, i.e. each element is divided by the sum obtained, yielding the weights of the criteria:

$$
\omega_{i}=\frac{\sqrt[m]{\Pi_{i}}}{\sum_{i=1}^{m} \sqrt[m]{\Pi_{i}}}=\frac{\sqrt[m]{\prod_{j=1}^{m} p_{i j}}}{\sum_{i=1}^{m} \sqrt[m]{\prod_{j=1}^{m} p_{i j}}}(i=1,2, \ldots, m) .
$$

To calculate the consistency index and relationship, the largest eigenvalue $\lambda_{\text {max }}$, corresponding to the calculated eigenvector (weights $\boldsymbol{\omega}$ ) should be known. It can be also roughly calculated. For this purpose, the following operations are performed:

5) The comparison matrix $\mathbf{P}$ is multiplied by the weight column $\boldsymbol{\omega}=\left(\omega_{1}, \omega_{2}, \ldots, \omega_{m}\right)^{T}$ :

$$
\begin{aligned}
\mathbf{P} \boldsymbol{\omega} & =\left(\begin{array}{ccc}
p_{11} & p_{12} \cdots & p_{1 m} \\
p_{21} & p_{22} \cdots & p_{2 m} \\
\vdots & \ddots & \vdots \\
p_{m 1} & p_{m 2} \ldots & p_{m m}
\end{array}\right)\left(\begin{array}{l}
\omega_{1} \\
\omega_{2} \\
\ldots \\
\omega_{m}
\end{array}\right)= \\
& =\left(\begin{array}{l}
p_{11} \omega_{1}+p_{12} \omega_{2}+\ldots+p_{1 m} \omega_{m} \\
p_{21} \omega_{1}+p_{22} \omega_{2}+\ldots+p_{2 m} \omega_{m} \\
\cdots \\
p_{m 1} \omega_{1}+p_{m 2} \omega_{2}+\ldots+p_{m m} \omega_{m}
\end{array}\right)=
\end{aligned}
$$




$$
=\lambda_{\max }\left(\begin{array}{l}
\omega_{1} \\
\omega_{2} \\
\ldots \\
\omega_{m}
\end{array}\right)=\left(\begin{array}{l}
\lambda_{\max } \omega_{1} \\
\lambda_{\max } \omega_{2} \\
\ldots \\
\lambda_{\max } \omega_{m}
\end{array}\right) .
$$

6) Each of the column elements obtained is divided by the respective weight $\omega_{i}$. If matrix $\mathbf{P}$ is ideally consistent, the relationships between all the elements will be the same. They will be equal to the largest eigenvalue $\lambda_{\max }$ being sought. If the relationships differ (which is usually the case in real calculation), the average relationship is taken as the largest eigenvalue $\lambda_{\max }$.

Let us illustrate the application of the algorithm described by a case study. We have the filled in matrix $\mathbf{P}$ for comparing the criteria elicited from an expert (Fig. 1).

$$
\mathbf{P}=\left(\begin{array}{cccccc}
1 & 3 & 9 & 8 & 2 & 7 \\
1 / 3 & 1 & 4 & 3 & 1 / 2 & 2 \\
1 / 9 & 1 / 4 & 1 & 1 / 2 & 1 / 9 & 1 / 3 \\
1 / 8 & 1 / 3 & 2 & 1 & 1 / 4 & 1 \\
1 / 2 & 2 & 9 & 4 & 1 & 3 \\
1 / 7 & 1 / 2 & 3 & 1 & 1 / 3 & 1
\end{array}\right)
$$

Fig. 1. A standard matrix elicited from an expert

The products of row elements $\Pi_{i}=\prod_{j=1}^{n} p_{i j}$ of matrix $\mathbf{P}$
are found (Table 2, row 2). For example, the products of the first row elements of the matrix are $\Pi_{1}=1 \cdot 3 \cdot 9 \cdot 8 \cdot 2 \cdot 7=3024$. Let us extract the sixth degree root (for the number of criteria $\mathrm{m}=6$ ) from the product obtained (Table 2, row 3 ). For example, the first element is $\sqrt[6]{\Pi_{1}}=3.802743$. Let us calculate the sum of the roots of the first row elements: $\sum_{i=1}^{6} \sqrt[6]{\Pi_{i}}=8.696670$. Now, let us divide each element of the third row by the sum obtained. In this way, we will get the weights of the criteria (Table 2, row 4). For example, the weight $\omega_{1}=3.802743 / 8.696670=$ 0.43726 .

Now, let us calculate the largest eigenvalue $\lambda_{\max }$ of the matrix. The product of matrix $\mathbf{P}$ and the weight column $\boldsymbol{\omega}=\left(\omega_{1}, \omega_{2}, \ldots, \omega_{m}\right)^{T}:$ is found as follows:

$$
\begin{aligned}
& \mathbf{P} \boldsymbol{\omega}=\left(\begin{array}{cccccc}
1 & 3 & 9 & 8 & 2 & 7 \\
1 / 3 & 1 & 4 & 3 & 1 / 2 & 2 \\
1 / 9 & 1 / 4 & 1 & 1 / 2 & 1 / 9 & 1 / 3 \\
1 / 8 & 1 / 3 & 2 & 1 & 1 / 4 & 1 \\
1 / 2 & 2 & 9 & 4 & 1 & 3 \\
1 / 7 & 1 / 2 & 3 & 1 & 1 / 3 & 1
\end{array}\right) \cdot\left(\begin{array}{l}
0.43726 \\
0.14487 \\
0.03255 \\
0.06032 \\
0.25093 \\
0.07407
\end{array}\right)= \\
&=\left(\begin{array}{l}
2.66773 \\
0.87539 \\
0.20008 \\
0.36514 \\
1.51574 \\
0.45058
\end{array}\right) .
\end{aligned}
$$

Let us divide the element of the column by the respective weight $\omega_{i}$ and get the eigenvalue:

$\lambda_{\max (1)}=2.667773 / 0.43726=6.1010$,

$\lambda_{\max (2)}=0.875366 / 0.14487=6.0426$.

Other relationships were calculated in a similar way:

$\lambda_{\max (3)}=6.1469, \lambda_{\max (4)}=6.0534$,

$\lambda_{\max (5)}=6.0405, \lambda_{\max (6)}=6.0832$.

The average value of the calculated eigenvalue is the estimate of the largest eigenvalue sought:

$\lambda_{\text {max }}=(6.1010+6.0426+6.1469+6.0534+6.0405+$ $6.0832) / 6=6.0779$.

In fact, when the computer programs are used, the largest eigenvalue $\lambda_{\max }=6.078$ does not differ from the roughly calculated value. The precisely calculated normalized eigenvector of weights, corresponding to it,

Table 2. The calculated weights of criteria

\begin{tabular}{lcccccc}
\hline & 1 & 2 & 3 & 4 & 5 & 6 \\
\hline$\Pi_{i}=\prod_{j=1}^{n} p_{i j}$ & 3024 & 4 & 0.2830635 & 0.020833 & 108 & 0.0714286 \\
\hline$\sqrt[n]{\Pi_{i}}$ & 3.802743 & 1.259921 & 0.2830635 & 0.524557 & 2.182247 & 0.644138 \\
\hline Weights $\omega_{i}$ & 0.43726 & 0.14487 & 0.03255 & 0.06032 & 0.25093 & 0.07407 \\
\hline
\end{tabular}


is equal to $\boldsymbol{\omega}=(0.43893 ; 0.14412 ; 0.03295 ; 0.06015$; $0.24961 ; 0.07423)^{T}$. The differences between accurately and approximately determined weights are also negligible.

These small differences observed in the relationships may be accounted for by the consistency of matrix $\mathbf{P}$. Actually, the consistency index calculated by formula (5) is equal to:

$$
S_{I}=\frac{\lambda_{\max }-m}{m-1}=\frac{6.078-6}{6-1}=0.0156,
$$

while the consistency relationship calculated by formula (6) is equal to:

$$
S=\frac{S_{I}}{S_{A}}=\frac{0,0156}{1,24}=0,0126 .
$$

Its value is smaller than 0.1 , i.e. the matrix is consistent and experts' estimates are in agreement.

When the matrix for comparing the criteria is ideally consistent, implying that the elements of all rows (and columns) are proportional, all estimates (relationships) of eigenvalues $\lambda_{\max (i)}(i=1,2, \ldots, m)$ are the same, exactly matching the largest accurately calculated eigenvalue $\lambda_{\text {max }}$

\section{A comparative analysis of one criterion in AHP method}

Though the AHP method has a mathematical basis, and, given the expert estimates of the criteria, can be used for determining the significance of the target objects, it still has some disadvantages, which are increasing with the increase of the number of criteria. Determining the significance of a particular pair of criteria for the object investigated, an expert should mentally 'weigh' the respective importance of other pairs of the criteria considered. When the number of criteria is large, it is a challenging problem for an expert. Practical application of AHP has revealed that only a few experts could avoid contradictions in filling in questionnaires (matrices), on which AHP approach is based, from the first time. Transitivity of the evaluation criteria is often violated, thus demonstrating the limitations of the method.

Therefore, the theoretical and practical problem of accurate significance determination of a large number of criteria arises.

One of the investigations (Ginevičius 2006) suggests a way of determining the weights of criteria by comparing only one criterion with the others based on the potential of the objects compared and interrelation- ship between the criteria describing the investigated phenomenon. As shown by calculations, the criteria weights determined by the method FARE correlate with the weights calculated by using AHP technique. Thus, the criteria weights could be determined by AHP, but the Saaty's scale of comparison should be extended.

A discrete scale in Saaty's AHP method, based on natural numbers 1-3-5-7-9, had not been chosen by chance. If the element $p_{i j}$ in matrix $\mathrm{P}$ were any rational number, it could be possible to obtain all the remaining elements by filling only one, say, the first row of the matrix. For example, if only the first criterion is compared with the others, i.e. only the first row of the matrix $\mathbf{P}$ is filled in, then, the elements of the second row could be obtained from the elements of this filled in row $\frac{\omega_{1}}{\omega_{1}}, \frac{\omega_{1}}{\omega_{2}}, \frac{\omega_{1}}{\omega_{3}}, \frac{\omega_{1}}{\omega_{4}}, \ldots, \frac{\omega_{1}}{\omega_{m}}$, by dividing them (beginning with the third element) by the second element $\frac{\omega_{1}}{\omega_{2}}$ :

$\frac{\frac{\omega_{1}}{\omega_{3}}}{\frac{\omega_{1}}{\omega_{2}}}=\frac{\omega_{2}}{\omega_{3}}=p_{23}, \frac{\frac{\omega_{1}}{\omega_{4}}}{\frac{\omega_{1}}{\omega_{2}}}=\frac{\omega_{2}}{\omega_{4}}=p_{24}, \ldots, \frac{\frac{\omega_{1}}{\omega_{m}}}{\frac{\omega_{1}}{\omega_{2}}}=\frac{\omega_{2}}{\omega_{m}}=p_{2 m}$.

Similarly, if the elements of the first matrix row are divided (beginning with the fourth element) by the third element of the row $\frac{\omega_{1}}{\omega_{3}}$, the third row elements would be obtained:

$p_{34}=\frac{\frac{\omega_{1}}{\omega_{4}}}{\frac{\omega_{1}}{\omega_{3}}}=\frac{\omega_{3}}{\omega_{4}}, p_{35}=\frac{\frac{\omega_{1}}{\omega_{5}}}{\frac{\omega_{1}}{\omega_{3}}}=\frac{\omega_{3}}{\omega_{5}}, \ldots, p_{3 m}=\frac{\frac{\omega_{1}}{\omega_{m}}}{\frac{\omega_{1}}{\omega_{3}}}=\frac{\omega_{3}}{\omega_{m}}$, etc.

It should be noted that the first elements of each i-th row (up to the main matrix diagonal elements $p_{i i}=1$ ) are obtained from the elements of the filled in i-th row of the matrix by applying the property of the inverse symmetrical matrix, i.e. $p_{j i}=1 / p_{i j}$.

The elements of the matrix columns (and rows) constructed in this manner will be proportional, i.e. the matrix is 'ideally' consistent.

In comparing objects (criteria) an expert should first rank them, i.e. number in a descending or ascending order according to their significance, then, determine the most important object and compare it with others. It is convenient to compare the most important criterion with the others because, in this case, all the elements in a row will be larger than or equal to unity. 
Let us demonstrate how it is possible to obtain the whole comparison matrix from the filled in row (under the condition that the matrix elements are rational numbers).

Let us take the elements of the first row of the previously analysed six-order matrix (Fig. 1):

$$
\left(\begin{array}{llllll}
1 & 3 & 9 & 8 & 2 & 7
\end{array}\right)
$$

We will have the opportunity to create an ideally consistent matrix, to calculate its largest eigenvalue and the corresponding weight vector and to compare them with the prior calculated value. As one can see, the expert thinks that the first criterion is most significant: all first row elements are larger than or equal to unity. Let us divide the first row elements of the matrix, beginning with the third one, by the second element of the row $p_{12}=3$. Then, we will get the second row elements: $p_{23}=9 / 3=3, p_{24}=8 / 3, p_{25}=2 / 3, p_{26}=7 / 3$. As a result, we have the first two rows of the matrix $\left(p_{21}=1 / p_{12}=1 / 3\right)$ :

$$
\left(\begin{array}{cccccc}
1 & 3 & 9 & 8 & 2 & 7 \\
1 / 3 & 1 & 3 & 8 / 3 & 2 / 3 & 7 / 3
\end{array}\right) .
$$

We can see that the elements of the first two rows are proportional, with the coefficient of proportionality of $1 / 3$.

In a similar way, the elements of the first matrix row are divided beginning with the fourth one by the third element of the row $p_{13}=9$. Then, the third row elements are obtained: $p_{34}=8 / 9, p_{35}=2 / 9, p_{36}=7 / 9$. Let us also calculate the elements of the remaining two rows. Then, we will get the comparison matrix:

$$
\mathbf{P}=\left(\begin{array}{cccccc}
1 & 3 & 9 & 8 & 2 & 7 \\
1 / 3 & 1 & 3 & 8 / 3 & 2 / 3 & 7 / 3 \\
1 / 9 & 1 / 3 & 1 & 8 / 9 & 2 / 9 & 7 / 9 \\
1 / 8 & 3 / 8 & 9 / 8 & 1 & 1 / 4 & 7 / 8 \\
1 / 2 & 3 / 2 & 9 / 2 & 4 & 1 & 7 / 2 \\
1 / 7 & 3 / 7 & 9 / 7 & 8 / 7 & 2 / 7 & 1
\end{array}\right) .
$$

The matrix $\mathrm{P}$ is completely consistent: the elements of all rows (and columns) are proportional. However, the scale of rational numbers was used instead of the Saaty's scale of 1-3-5-7-9. The consistency index of the matrix $S_{I}$ calculated by formula (5) and the consistency relationship $S$ calculated by formula (6) are equal to zero. Let us determine the vector of the criteria weights, matching the comparison matrix:

$\tilde{\boldsymbol{\omega}}=(0.4520 ; 0.1507 ; 0.0502 ; 0.0565 ; 0.2260 ; 0.0646)^{T}$.
The previously calculated vector of weights was as follows:

$$
\begin{aligned}
\boldsymbol{\omega}= & (0.43893 ; 0.14412 ; 0.03295 ; 0.06015 ; \\
& 0.24961 ; 0.07423)^{T} .
\end{aligned}
$$

As we can see, there are some differences between the obtained weights and weights of all the criteria in the matrix previously calculated by an expert. However, these differences are negligible, therefore, the obtained weights $\tilde{\boldsymbol{\omega}}$ could be used for multicriteria evaluation. It should be noted that the method of comparing only one criterion cannot be considered an AHP alternative. The logic and the philosophy of AHP approach are more sophisticated. In comparing each criterion (object) with the others, an expert should determine the full implication of any particular criterion, evaluating its influence on the considered economic, social or technological phenomenon from various perspectives. The application of AHP based on the comparison of one criterion may be recommended:

a) at the initial stage, when an expert has not yet grasped the idea of the method and its requirements;

b) when the number of the evaluation criteria (objects) is large (more than ten);

c) when relative significance of criteria should be determined in the preliminary weight evaluation process and then compared to that obtained by using other (direct or indirect) methods of weight determination.

\section{Conclusions}

1. A method relying on analytic hierarchy process (AHP) has a mathematical basis and may be suggested for determining the significance (weights) of the objects (e.g. criteria) being evaluated. However, the method is rather complicated because a matrix of estimates' comparison may be inconsistent (in discordance).

2. AHP technique is based on a mathematical theory of eigenvalues and eigenvectors. It can be practically used by applying special computer programs. The present paper demonstrates a possibility of calculating the approximate criteria weights and determining the criteria of consistency.

3. Pairwise comparison of criteria suggested in AHP approach is getting complicated, when the number of the objects compared is increasing. To solve this problem, the paper offers an algorithm, as well as demonstrating a possibility of determining the preliminary weight estimates by comparing only one criterion with the others. 
4. The option based on comparing a single criterion cannot be considered an AHP alternative. It can be used at the initial stage of AHP application, particularly, in the environment when the number of evaluation criteria is large and for comparing the criteria weights obtained by various methods.

\section{References}

Banaitienè, E.; Banaitis, A.; Kaklauskas, A.; Zavadskas, E. K. 2008. Evaluating the life cycle of a building: a multivariant and multiple criteria approach, Omega- International Journal of Management Science 36(3): 429-441.

Beshelev, S. D.; Gurvish, F. G. 1974. Mathematical and statistical methods of expert evaluation. Moscow: Statistics (in Russian).

Cheng, E. W. L.; Li, H. 2004. Contractor selection using the analytic network process, Construction Management and Economics 22: 1021-1032.

Dikmen, I.; Birgonul, M. T. 2006. An analytic hierarchy process based model for risk and opportunity assessment of international construction projects, Canadian Journal of Civil Engineering 33: 58-68.

Figueira, J.; Greco, S.; Ehrgott, M. 2005. (Eds.). Multiple Criteria Decision Analysis: State of the Art Survey. Springer.

Ginevičius, R. 2006. Multicriteria evaluation of the criteria weights by multicriteria methods based on their interrelationships, Verslas: teorija ir praktika [Business: Theory and Practice] 7(1): 3-13 (in Lithuanian).

Ginevičius, R. 2008. Normalization of quantities of various dimensions, Journal of Business Economics and Management 9(1): 79-86.

Ginevičius, R.; Podvezko, V. 2004. Quantitative assessing the accuracy of expert methods, Engineering Economics 5(40): 7-12.

Ginevičius, R.; Podvezko, V. 2006. Assessing the financial state of construction enterprises, Technological and Economic Development of Economy 12(3): 188-194.

Ginevičius, R.; Podvezko, V. 2007a. Some problems of evaluating multicriteria decision methods, International Journal of Management and Decision Making 8(5/6): 527-539.

Ginevičius, R.; Podvezko, V. 2007b. Complex assessment of sustainable development of state regions with emphasis on ecological and dwelling conditions, Ekologija 53: 41-48.

Ginevičius, R.; Podvezko, V. 2008a. The problem of compatibility of various multiple criteria evaluation methods, Verslas: teorija ir praktika [Business: Theory and Practice] 9(1): 73-80 (in Lithuanian).

Ginevičius, R.; Podvezko, V. 2008b. Multicriteria graphicalanalytical evaluation of the financial state of construction enterprises, Technological and Economic Development of Economy 14(4): 452-461.

Ginevičius, R.; Podvezko, V. 2008c. Housing in the context of economic and social development of Lithuanian re- gions, International Journal of Environment and Pollution 35(2/3/4): 309-330.

Ginevičius, R.; Podvezko, V.; Andruškevičius, A. 2004. Determining technological effectiveness of building systems by AHP method, Ūkio technologinis ir ekonominis vystymas [Technological and Economic Development of Economy] 10(4): 135-341 (in Lithuanian).

Ginevičius, R.; Butkevičius, A.; Podvezko, V. 2006. Complex evaluation of economic development of the Baltic States and Poland, Ekonomický Časopis [Journal of economics] 54(9): 918-930.

Ginevičius, R.; Podvezko, V.; Andruškevičius, A. 2007. Quantitative evaluation of building technology, International Journal of Technology Management 40(1/2/3): 192-214.

Ginevičius, R.; Podvezko, V.; Bruzgè, Š. 2008a. Evaluating the effect of state aid to business by multicriteria methods, Journal of Business Economics and Management 9(3): 167-180.

Ginevičius, R.; Podvezko, V.; Raslanas, S. 2008b. Evaluating the alternative solutions of wall insulation by multicriteria methods, Journal of Civil Engineering and Management 14(4): 217-226.

Hsueh, S.-L.; Perng, Y.-H.; Yan, M.-R.; Lee, J.-R. 2007. Online multicriteria risk assessment model for construction of joint ventures in China, Automation in Construction 16: 607-619.

Hwang, C. L.; Yoon, K. 1981. Multiple Attribute DecisionMaking Methods and Applications, A State of the Art Survey. Springer Verlag, Berlin, Heidelberg, New York.

Kaklauskas, A.; Zavadskas, E. K.; Raslanas, S.; Ginevičius, R.; Komka, A.; Malinauskas, P. 2006. Selection of low-e windows in retrofit of public buildings by applying multiple criteria method COPRAS: A Lithuanian case, Energy and Buildings 38: 454-462.

Kaklauskas, A.; Zavadskas E. K.; Trinkūnas, V. 2007a. A multiple criteria decision support online system for construction, Engineering Applications of Artificial Intelligence 20(2): 163-175.

Kaklauskas, A.; Zavadskas, E. K.; Banaitis, A.; Šatkauskas, G. 2007b. Defining the utility and market value of real estate: a multiple criteria approach, International Journal of Strategic Property Management 2(11): 107-120.

Ma, J.; Fan, Z.-P.; Huang, L.-H. 1999. A subjective and objective integrated approach to determine attribute weights, European Journal of Operational Research 112 (2): 397404.

Mansouri, S.A.; Moattar Husseini, S.M.; Newman, S.T. 2000. A review of the modern approaches to multicriteria cell design, International Journal of Production Research 38(5): 1201-1218.

Morkvėnas, R.; Bivainis, J.; Jaržemskas, J. 2008. Assessment of employee's knowledge potential in transport sector, Transport 23(3): 258-265.

Podvezko, V. 2006. Multicriteria evaluation under uncertainty, Verslas: teorija ir praktika [Business: Theory and Practice] 7(2): 81-88 (in Lithuanian). 
Podvezko, V. 2007. Determining the level of agreement of expert estimates, International Journal of Management and Decision Making 8(5/6): 586-600.

Podvezko, V. 2008. Comprehensive evaluation of complex quantities, Verslas: teorija ir praktika [Business: Theory and Practice] 9(3): 160-168 (in Lithuanian).

Saaty, T. L. 1980. The Analytic Hierarchy Process. M. GrawHill, New York.

Saaty, T. L. 2005. The Analytic Hierarchy and Analytic Network Processes for the Measurement of Intangible Criteria and for Decision-Making, in Figueira, J.; Greco, S.; Ehrgott, M. (Eds.). Multiple Criteria Decision Analysis: State of the Art Surveys. Springer, 345-408.

Shikin, Y. V.; Chartishvili, A. G. 2000. The use of mathematical methods and models in management. Moscow, Delo (in Russian).

Su, Ch.-W.; Cheng, M.-Y.; Lin, F.-B. 2006. Simulation-enhanced approach for ranking major transport projects, Journal of Civil Engineering and Management 12(4): 285-291.

Taha, H. 1997. Operations research. An introduction. Sixth edition. New Jersey: Prentice Hall.

Turskis, Z.; Zavadskas, E. K.; Peldschus, F. 2009. Multi-criteria optimization system for decision making in construction design and management, Inžinerine ekonomika - Engineering Economics 1(61): 7-17.

Ustinovichius, L.; Zavadskas, E. K.; Podvezko, V. 2007. Application of a quantitative multiple criteria decision making
(MCDM-1) approach to the analysis of investments in construction, Control and Cybernetics 35(2): 251-268.

Vamvakeridou-Lyroudia, L. S.; Savic, D. A.; Walters, G. A. 2006. Fuzzy hierarchical decision support system for water distribution network optimization, Civil Engineering and Environmental Systems 23(3): 237-261.

Viteikiene, M; Zavadskas, E. K. 2007. Evaluating the sustainability of Vilnius city residential areas, Journal of Civil Engineering and Management 13(2): 149-155.

Zavadskas, E. K.; Kaklauskas, A. 2007. Mehrzielselektion für Entscheidungen im Bauwesen [Multi-attribute Decisions in Construction]. Fraunhofer IRB Verlag (in German).

Zavadskas, E. K.; Vilutienè, T. A. 2006. A multiple criteria evaluation of multi-family apartment block's maintenance contractors: I-Model for maintenance contractor evaluation and the determination of its selection criteria, Building and Environment 41: 621-632.

Zavadskas, E. K.; Kaklauskas, A.; Turskis, Z.; Tamošaitienė, J. 2008a. Selection of the effective dwelling house walls by applying attributes values determined at intervals, Journal of Civil Engineering and Management 14(2): 85-93.

Zavadskas, E. K.; Turskis, Z.; Tamošaitienė, J.; Marina, V. 2008b. Multicriteria selection of project managers by applying grey criteria, Technological and Economic Development of Economy 14(4): 462-477. 